\title{
Aerotecnica M\&S 100 Years Ago: the Italian Civil Aviation in 1921
}

\author{
Aldo Frediani ${ }^{1}$ - Vittorio Cipolla ${ }^{1}$ Sergio De Rosa ${ }^{2} \cdot$ Paolo Gasbarri $^{3}$
}

Accepted: 4 November 2021 / Published online: 9 December 2021

(c) AIDAA Associazione Italiana di Aeronautica e Astronautica 2021

Dear reader,

This issue concludes volume the first century of life of Aerotecnica and we are facing to the second century of history of our journal with gratitude towards who founded and managed it and, also, towards the authors of the papers all this century along.

Since 1921 our journal has never ceased to publish scientific articles and to be an important tool for the dissemination of scientific and technical cultures in Aerospace; even during World War II.

Dear reader, according to the custom that we have inaugurated in n. 1 of this volume 100, we report the translation into English of an article published in 1921 by E. Pistolesi and A. Zezi. The article is part of the debate on the future of commercial aviation, a topic on which U. Nobile had published, in the same volume 1 , a famous article that we published in no. 3 of this volume 100. In his vision of the future, U. Nobile attributed to the airship the driving role in the civil transport of the future, starting from the observation of the inadequacy of aircraft constructions to withstand high loads. The current (of 1921) state of calculation methods and existing technologies for the construction of aircraft, could have supported its prediction. In this regard, our readers have read Verduzio's translation on aircraft and airship constructions at a time when aluminum sheets were not yet available as a structural coating. Pistolesi, after publishing in volume 1 a famous article on the theory of vortices in Aerodynamics and a proposal for the study of propellers (see the introduction to n. 2 of this volume 100), addresses the general theme of the future of air transport but with a different vision from that of Nobile. His article, entitled "Italy and civil aviation", of which we report the English translation in this premise, is

Aldo Frediani

aldo.frediani@unipi.it

Università di Pisa, Pisa, Italy

2 Università Federico II Napoli, Naples, Italy

3 Università La Sapienza Roma, Rome, Italy a manifesto of scientific and technical progress addressed to the leaders of the national policies of Italy but, as the reader will see, the document is fully valid in every context and in every time; even today after 100 years.

Happy reading, dear reader.

\section{Italy and the Civil Aviation}

(Report compiled in January 1921 by a group of membersamong them the engineers who supported the majority of the work E. Pistolesi and A. Zezi-with the intention, then no longer implemented, of disseminating it to the public for propaganda purposes).

\subsection{Foreword}

Italy, which terminated the conflict with a powerful air force and called by its political and geographical position to participate in the World Air Transport Organization, has not yet competed with the other nations to prepare a civil aviation. Nor does he realize at all of the very serious importance of the fact.

'This is the painful observation of the moment.

To highlight the causes of this, to try to remove them, to prick the self-love of Italians by showing what is done abroad and what is done by us, to point out the way to follow: this is the aim of this publication.

\subsection{The Air Force During the War}

Nothing in this topic is worth as much as the eloquence of numbers.

An interesting statistic from the Technical Directorate of Aviation gives us the following data (Table 1):

It is, therefore, easy to explain that, while at the time of mobilization, Italy had only a small number of aircraft and very few airships, at the end of the war there were no less than 18 squadrons of fighter aircraft, 6 for infantry service, 
Table 1 Italian aircraft industry statistics

\begin{tabular}{lcl}
\hline & In 1910 & In 1918 \\
\hline Manufactured aircraft & 3 & 6500 \\
Manufactured engines & 13 & 14,800 \\
Pilots & 2 & 2500 \\
\hline
\end{tabular}

Table 2 Density of the aircraft on the combat line

\begin{tabular}{llll}
\hline & Italy & France & UK \\
\hline Fighter aircraft & 15 & 15 & 50 \\
Recognisance aircraft & 18 & 18 & 23 \\
Bomber aircraft & 10 & 10 & 40 \\
\hline
\end{tabular}

28 squadrons of reconnaissance planes, 13 squadrons of bombers and, also, 24 airships, of which 9 for bombing and 15 for exploration on the sea, 22 aerostatic groups with observatory balloons.

The development of aviation was no less important to the other belligerents and to give an idea of the density of the aircraft on the combat line, we report the number of them along every $10 \mathrm{~km}$ of battlefront (Table 2):

No less intense development experienced the Air Force in the Central Empires, both for airplanes and for airships.

The foregoing indicates the importance of the mass of aircraft; but the war qualities of the aerial machines had no less rapid progress.

Reconnaissance on land by airplanes and sea by seaplanes and airships reached indisputable importance. No movement of any magnitude, no major target for artillery, no detail of the fortifications can escape the aircraft, which, passing quickly into the enemy sky, portrays the ground in a series of photographs. Then, on the identified target, soon begins the hail of the projectiles; and the one who points the cannon is the aviator, who from his aircraft corrects the shots and directs them precise into the sign.

At sea the submarine pitfall found its biggest enemy in the airship. This, sailing slow and low on the water, peers into the bottom of the sea, patiently searching for underwater mines and enemy submarines.

Of the former, it signals the presence to minesweepers. Of the submarines, it follows all movements, stubbornly remaining on their vertical, to hit them with bombs or with the cannon it carries. When attacked, it fast runs away gaining altitude.

The airplane and the airship led the offense where the cannon couldn't get. The large amount of high explosive that can carry a squadron of aircraft or an airship, the smallness and mobility of the former, the silence and shooting accuracy of the second, made these machines terrible instruments of war.
To the large airplanes capable of heavy loads, was then added the work of light and fast devices, which brought the offense to the heart of the enemy state, with a great moral effect. So, our SVA flew over Vienna. They did not make any casualties; but this was only for the generous spirit of our aviators, proud just to show that the wings of Italy had the undisputed dominion of the sky.

Towards the end of the war, infantry aircraft appeared; they fought flying close to the ground as cavalry once fought in the open field. Not the nets, not the enemy fire were unsurpassable obstacles for them.

In short, the aerial weapon multiplied the faculties of fighter, allowed him to take his eye and camera everywhere; to scrutinize the depths of the sea; to strike at the heart of the enemy.

The war, which had become a war of peoples, had found a profound imbalance between the means of offense and the means of defence; the field fortification had victory over the cannon, the trench on the machine gun, the minefield on the warship. The air weapon filled that imbalance, no defence was valid against it, absolutely.

The air weapon could not effectively fight with the air weapon. And the fighter plane was born, fast as an arrow, lightning in attack like a bird of prey. Piloted by brave men, these aircraft launched the assault on the enemy aircraft and defended the friends engaged into their feats of war.

This is how the air weapon got up more and more from the ground; the high altitudes, the high speeds, the agility of its machines, the possibility of flight in the night made them very difficult targets. In vain, powerful reflectors rummaged through the sky; in vain, the anti-plane gunners launched large masses of fire, the aerial bomber passed; almost always returned to his camp. Where this efficiency comes from? in the following lines of the response.

The technical progress during the war was impressive. Not tidy or methodical, but impressive. It was necessary to be quick and all was quick. The needs of war had to be the main ones and they had all priorities indeed. Before the war, the speed of an airplane was not more than $150 \mathrm{~km}$ per hour on average and climbed slowly to no more than $4000 \mathrm{~m}$ of altitude. At the end of the war, the speed exceeded $250 \mathrm{~km}$ per hour, the altitude was $8000 \mathrm{~m}$ and it did not take more than $10 \mathrm{~min}$ to reach $4000 \mathrm{~m}$ of altitude. A no less significant increase had the payload and the distance to be travelled without a stopover.

We remember two Italian creations: the Caproni and the SVA; the first brought $1000 \mathrm{~kg}$ of high explosive over the enemies.

One main feature was developed during the war: agility. The flight became safe and daring. Those stunts that once were the rashness of a few pilots, became common exercises. There is no fighter pilot today who does not casually perform 
the circle of death (looping), inverted flight, the tonneaux and spin that was previously synonymous with death.

And what about the airship? From that prudent navigator who was at the beginning of the war, he took courage, acquired in the simplicity of construction, speed, maximum altitude, armament power and became capable, even with small cubature, of high loads and large autonomy.

Italian 1800 cubic meter airships could carry at a high altitude no less than $2000 \mathrm{~kg}$ of explosives and at low altitude $5000 \mathrm{~kg}$ of material; a small unit of 3600 cubic meters made sea cruises of 14 and $15 \mathrm{~h}$; the Zeppelin. L. 59 flew non-stop from Bucharest to Chartoum and back; $7000 \mathrm{~km}$. in $96 \mathrm{~h}$; in the immediate post-war the English R. 34 crossed twice the Atlantic with a safe flight.

\subsection{The Italian Aeronautics in the Post-War}

If the history of the Italian air force during the war is great, the post-war history is bad.

The powerful war machine had to be turned into an industrious peace machine; but it was destroyed.

The liquidation of materials and the demobilization of personnel were carried out without looking to the future. Some people could say: but who could have been able to predict the future, above all by dealing with such a new medium? That is right. This is precisely why we needed more prudence and prudence: not only was the superfluous abolished but it was cut in its heart.

The General Directorate of Aeronautics was later created: it had to represent the first experiment in civil Aeronautics. Everyone knows what he did and how it finished.

Was it the fault of Men or of things? Both. Men were overwhelmed by the general chaos of the post-war period. Technicians and pilots were suffocated. In any occasion, the political opportunities prevailed over the technical or industrial convenience; the political vision, indeed, dominated sovereign as the Raid Rome-Tokyo ${ }^{1}$ teaches!

The scientific, experimental and technical bodies remained without any direction at the mercy of the general chaos.

Denied the means, removed all contact with the stream of general progress, disgusted the staff, the bodies, on whose fruitful work had to be based the best hopes, were dismembered. We are grateful to the few remaining technicians for the little that the air force has done in the post-war period; but how many obstacles have to be overcome!

At the same time, the despotism of bureaucracy arose, every activity was hindered; every vital issue, quickly

\footnotetext{
${ }^{1}$ Editor's note: On the raid Rome-Tokyo. preceded by so much rhetoric and followed by so many diatribes, see a serene word in L'Aeronautica. year III. n. 4. 1920.
}

examined and resolved by the technical bodies, gets miserably bogged down in the central bodies.

But if aeronautics wants to live, it has to speed up. Of the past, not only the systems must be abandoned, but also the heavy legacy.

The laborious liquidation of war must be carried out in the best possible way and the active bodies must be freed from such a burden. It is in the future that we must look not at the past.

The consequence of all this is a general mistrust.

And it is justified. What do we do to win it? There is faith and courage: initiatives are not missing; but how to encourage them?

Those who support the future of civil aviation are the object of pity or ridicule.

This mistrust must be stopped. This is the purpose of these pages.

\subsection{What the Aeronautical Problem Looks like}

All have faith in the air force of war; only a few on aeronautics of peace. Very few finally understand that the powerful air force of war can only exist if there is a thriving air force of peace.

That this is true it is easy to convince.

When will a state have a powerful war air force? Immediate answer: when it has many and excellent aerial machines, many and excellent pilots to conduct them, large workshops to build them, numerous airports to shelter them, wellorganized general services.

Now, neither all this can be improvised at the outbreak of a war nor we can maintain in continuous efficiency a powerful air army, of which not only our country but others, much richer than us, could bear the enormous expense. For this reason, it is enough to think that the continuous, turbulent progress would force the frequent renewal of all the material.

So, what can be done? There is only one means; give aeronautics its own vitality; to ensure that it finds in its own progress the reason for living and that it achieves an immediate purpose with its own development. In other words, aeronautics must enter the normal life of the nation: aeronautics must become civil.

Thus, only if a war will break out (God save from it) the air weapon will immediately have impressive means. There will be no shortage of technicians and workers already specialized in the construction of aerial machines: numerous airports will already be ready; general services (aerology, meteorological, radiotelegraphic, etc.) will already have a solid organization; pilots and, to some extent, even peace machines will quickly turn into pilots and war machines.

But the subject presents some other important aspects.

From a certain point of view, a comparison between aeronautical and mechanical industry is permissible. Does 
mechanical industry have to live in Italy? If it disappears, we will become tributary to foreign countries in peacetime, slaves in wartime. The same question could be asked for the aircraft construction industry if it were to weigh on the national economy in any way; and the same answer would have to be given. We note, however, a circumstance in favour of Aeronautics: it finds almost entirely in the country the few raw materials it needs; it requires a very limited use of driving force and a very wide choice of labour. It, therefore, responds perfectly to our economic and social conditions.

Other circumstances come out of the material field, but they are no less important for this. It is, in fact, vain to demand progress if technology does not feel the rude contact with the difficulties of practice: the library or laboratory scholar will constitute a rich scientific patrimony; but the aerial machine capable of struggling with the elements, the workshop capable of building it, the man capable of piloting it will arise only from experience. And a real experience will only be provided by a true continuous and extensive service.

In the meantime, we note only general mistrust. As we have already said, few have faith in peace aeronautics.

Well, this faith must and can be born. Since he was born, man was harassed by a burning desire: the conquest of heaven. This desire is fulfilled today: the conquest of heaven is a fait accompli. Is it possible that it should serve only to sow death? This repels reason and hurts feelings.

Is there any doubt whether aerial machines are capable of performing a civilian task? Those who look at them today may be right. But it was already said: the process of aeronautics war performed mainly in war and for war. And it was made out that it was necessary to take the needs of war into account and that only these were effectively considered. But the technique has not dictated the last yet. It will solve the problem of civil air transport. Soon, we will tell how.

The science of aeronautics is still a baby-girl: only today, rising, as in almost all human manifestations, after practice, it replaces its laws with empiricism. And tomorrow it will give us the device that meets all civil needs.

All the great innovations that human genius was able to generate, met distrust on the beginning. And this was difficult to fight because it had powerful allies in misoneism and sometimes even-in fear. When the first railway was built, when the first cars appeared, who wanted to entrust their lives or wealth to them? Every misfortune seemed to decree the disappearance of the new means. And, instead, these imposed themselves because they became a need.

So, the great innovation of flight will impose or, better, it will not have to impose itself, it will not have to wait to become a need. It already is; it has always been, a living and pungent need of the human soul.

There are those who observe that these are words, they want facts. There are significant facts: we will report them shortly. It will be said that they are few and sporadic: and indeed they are. But they will so be for a long time to come if the mistrust of most people does not cease to pose an obstacle.

This is a vicious circle. It must be broken. Who will solve the problem of civil aeronautics will be the technical progress that has already solved that of the air force, of war.

Technical progress, if not contrasted, will make aerial machines suitable for civil services. What requirements should these services meet? It is easy to enumerate them: safety, regularity, speed, economy and, for passengers, comfort.

Safety and economy: these are the most questioned qualities while, as far as the regularity of the service is concerned, we must admit that much depends on the organization of areological information and, in general, of ground services. In fact, no one will deny that technical progress will make it easier to leave and arrive, on land and on water, thus removing the greatest obstacle produced by bad weather.

And as for comfort, is there anyone who doubts that technology will not be able to offer all desirable comfort to sky travellers? But let us move on to the two main requirements: safety and economy. At the first, little weight was given during the war, and rightly so. The air machine of war was a means of destruction: it had to preserve itself as much as was necessary to be able to destroy. A large margin of safety would have been harmful.

But the needs of the civil services are quite different: the technology knows it. It studies the problem; it has already solved it partially; it will solve it entirely.

When the machine will be made more stable and more robust; perfected the engines \&multiply their number on board; organized with sound criteria and in large part the ground services, the flight will become one of the safest means of locomotion.

It is said that there are too many unfavourable circumstances, that the air vehicle is a too delicate mechanism, that if a gear stops, the consequences are fatal. And by rail? The traveller of a train launched at Km. 100 per hour, does not think that his life depends on a vast and complicated service of signals and exchanges. A missing or misinterpreted signal, a wrong exchange can produce a disaster.

Air disasters happened, and some are very painful. But think of the conditions in which we have flown so far: war machines, pilots who still have the bold mentality of war, disorganization on the ground.

If we exclude cases in which imprudence overloaded the aircraft beyond the limits assigned by the manufacturer; in which the areological forecast was not available or not taken into account properly; in which the telegraph or telephone transmitted a piece of information late which, known in time, would have avoided serious consequences; thus, instead of despairing, it should be surprising that there have been so 
few accidents; it must be admitted that the flight, carried out with precautions not dissimilar to those required for other means of transport, is intrinsically safe. Finally, consider this: that the means of air transport is not, whatever it may appear at first glance, less tied to the ground than the other means that actually run on this and that, only when the terrain is strongly organized, we can speak of air navigation; today, this is first and foremost a problem of terrain. ${ }^{2}$

And now let us move on to the question of cost. The cost must be associated with the question of speed, in this as in any other means of transport. Speed and economy are two characteristics that merge into just one: the commercial value of the vehicle. Don't you often spend more in order to get there earlier?

Now, air transport, in its forms of heavier and lighter than air, meets variously these two needs.

The airplane is for high speeds. Indeed, it can be said that it obeys the so-called law of speed or, in a nutshell: the cost depends above all on the length of the journey; speed is paid very little. So, for example: going from Rome to Paris by airplane will cost almost the same, whether it takes eight or four hours.

From such a law, it follows that the airplane will have luck where the speed will have value. Those who consider time as money will find a cheap means in the airplane.

The airship will develop with another law: the law of cubature. A transport at given speed costs as less as the larger is the airship. Moreover: not varying the shipping cost of transport and increasing the volume of the airship, the speed increases. These statements, true within very wide limits, show that the large airship has wide elasticity of use.

Of course, in this question of the cost of air transport, we must avoid an error of method: the error of comparing air transport with rail, car, etc. In the field of transport, as in any other one, every means is used for the purpose for which it has been constructed. Vice versa, given the purpose, one means of transport achieves it more easily than the others. We, therefore, need to be very careful to make useful comparisons. Since the cost of each means is in correspondence with the needs it satisfies.

\footnotetext{
${ }^{2}$ Editor's note: The magnitude of this problem is greater than it might appear at first glance. The result of the experiences made so far has shown that between the two airports of the route it is necessary to intersperse a field of possible landing every $75 \mathrm{~km}$. and in foggy places or intense traffic every $50 \mathrm{~km}$ with all the related services. The minimum size for each field is 25 hectares $(500 \times 500 \mathrm{~m})$. Just think of the thorny practices for the expropriation of land, especially in countries with very fractional ownership (in the recent routes in France the land for some fields had to be expropriated up to 60 owners!) and the building and levelling works to be carried out in them, as well as the organization of all the necessary services, to get an idea of the extent of the problem for the construction of an air route.
}

The same caution necessary when dealing with the comparisons between ground transport and air transport is also needed between the two types of this last transport that is, between the airship and the airplane, in respect of which, sometimes, it raises the idle question of whether the victory will be for one rather than the other.

Now it is necessary once again to repeat that there will be no victory because there has never been and there will be no battle. Both have the right to life: each to his own.

They have profoundly different characteristics: they are, therefore, able to meet different needs.

Why do we want to compare them? What do they have in common? Only this: that they travel in the air. And thus, why do not compare the motorcycle with the train?

And that would be enough. But to avoid a return to this vain subject, we will highlight the qualities of the two air locomotion systems: it will be a confirmation of the foregoing.

The airship has the advantage of being able to vary its speed down to a standstill and, therefore, has a wide possibility of repairing any on-board failures, of sailing safely at low altitude, of travelling at night, and, relatively, even in foggy weather, it will have comfort in carefully observing the terrain or sea below and enjoying the landscape; it does not require a route organization with several makeshift fields.

Instead, the airplane has raised the value of speed to its highest degree, a value that, as said before, does not significantly influence the cost, and allows, relatively easily, of defying adverse weather conditions. This latter prerogative beneficially affects the regularity of the service that an airplane can provide.

What is the conclusion, if not that the heaviest and the lightest will not have to fight as competitors, but tend to collaborate to satisfy particular needs?

\subsection{What is Currently Being Done}

England, before the other states, faced the problem of civil aviation with energy. Nor is it any wonder: many reasons pushed it; many circumstances helped her.

Among the reasons, the first is the need for defence. The British Isles had joined a fleet that dominated the sea and England felt safe. But now another infinite Ocean has opened up to man: that of air. England is again in danger if it is not the master of it: and it does everything to become one. Second, the need for rapid communication with the parts of his empire: that is, with all parts of the world.

Among the favourable circumstances, the first was the coming out of the war with a military aviation powerful in quality and quantity. The second is the very strong ability of organization of the Anglo-Saxons. 
The war had just ended and, precisely, on February 12th, 1919, the Government announced the establishment of a Department for Civil Aviation to the House of Commons: immediately the study of the problems related to the transition from war to peace was undertaken on May 1st, 1919 the Civil Aviation began to live and with what fervour and action can be judged by the summary news that follow.

Agreements were established with foreign countries for air traffic, transit concessions and landing permits. The first result was that the British aircraft could carry out active propaganda work for the English industry by visiting the main cities of France, Belgium, Netherland, Sweden, Norway, Denmark, Switzerland and Spain.

A reconnaissance on long routes between distant parts of the empire was carried out. So, Egypt and India are connected by the Cairo-Karachi route, which is normally used for military purposes and, with recent deliberation, it will be used for civil services as well, with a weekly trip in both directions. It is about 40 degrees of longitude and something like $4000 \mathrm{kms}$. In addition, the route from Egypt to Cape Town (Cairo-Cape Town) has already established a complete chain of landing fields; the part of the route included in the Territories of the Union of South Africa is going to be used for civilian transport; the operation of the entire route is supposed to start early. It is going to extend across Africa for almost $70^{\circ}$ latitude, or something like $8000 \mathrm{kms}$. Another important reconnaissance of the route was then carried out between India and Australia.

As early as May 1st, 1919, a regulation for air navigation was already operative, meanwhile in Italy all private aeronautical activity is currently suspended because of the lack of it. The English regulation was not born perfect: the practice has shown the opportunity of some tweaks; but precious time was not lost in the meantime. The aeronautical legislation is a very important problem for the development of air navigation: not only a profane in aeronautics, but also those who are involved in it, whether pilots or technicians, have understood the vital importance of air law so far. England is worthy of praise for having first understood!

The aircraft, the air personnel and the manager in the airports must be equipped with official certificates for the qualification to the service, In eight months of 1919, 292 were issued to airfields, 258 to aeronautical technicians, 374 to pilots, 241 to aircraft. In Italy, to this day, no more than eighty airplanes have permission to fly.

Also the various services took an adequate development in England.

The British Areological Service, although its activities are also beyond aeronautics, has been placed under the Department of Civil Aviation because of its essential importance to it.

The ground news communications service was entrusted to the normal telegraph and telephone network. (Not so would it be dared to recommend the same in Italy!). Then, of course, there is a radio and telegraph service for communications with in-flight aircraft and for the rapid transmission of news between London and Paris, which have long been linked, as we shall see, to a regular air service. Thus, the weather reports are transmitted by radio-telegram and three times a day the weather forecast is launched into space.

For signals, especially at night, there are agreements with the Headlights Office; important experiments are underway and a radiogoniometric service or radio is being organized to indicate the route to aircraft in flight, as we shall mention later on.

Similarly to what already exists for marine navigation, an aerial navigation map has begun: so, for the London-Paris there is no longer a lack of good maps, specially drawn up, and flight instructions with all the indications relating to the available airports and services.

A special Office is responsible for collecting and sharing the news: it collects news on the scientific and practical activities of other countries and share them with British manufacturers; in just two months of 1919 as many as 45 bulletins were issued. Press releases are then sent from this office.

We want to mention one last service to point out all the technical and moral utility: the accident service.

As soon as an accident of some severity occurs, it must be reported to the Department. This immediately sends technicians in charge of a thorough investigation to the scene; they, having ascertained the causes, will give way to eliminate them without any doubt. A statistic of the accidents is then made and published. Some will think that this is dangerous: that it will destroy confidence, supposed there was some. Far from it: the painful figures are so small that the effect is the contrary.

As a curiosity, we add that an air customs service is not missing in England: some airports have a special Office and any landings are the subject of investigations.

All this impressive work of which we gave an idea was done in October 1919 by the Department of Civil Aviation with a little, but well paid, staff; 144 employees (53 in concept and 91 in order) with $£ 50,000$ in salaries in total.

A proper air transport service is not set up inside the UK: it would find an overwhelming competitor in the excellent rail service. Totally different is the condition of the airlines which have regular service of passengers, mail and cargo between London and Paris, between London and Brussels, between London and Amsterdam. The 'speed' factor is of paramount importance to them and gives air transport great advantages over ordinary transport. The postal surtax for the first two lines is 2 pence/ounce (about $0.40 / 10$ gr. with the unity exchange rate) and of 3 pence/ounce (about 0.60 lire/10 gr) for the terrestrial traffic. 
Now, let us give an idea of the intensity of air traffic between England and the continent, reporting the following data:

In the twelve months from August 1919 to August 1920, the records of the British airports marked 1455 aircraft departing and 1325 arriving. In addition to the English, there were French, Belgian and even Swiss: none of Italians.

In the fifteen months from May 1919 to July 1920, as already mentioned, 82,664 passengers were transported, a total of 1,750,000 km were flown and, moreover, the movement of goods almost reached $90,000 \mathrm{~kg}$.

In six months of 1920, a total of 52,000 letters were finally transported.

The British Government does not grant direct subsidies to private companies, but in any way facilitates their activity through the action of the Department mentioned above and by taking care of all the general air traffic services.

The ground organization counts in Great Britain over fifty civil and as many military airports, which the civil air transport can use in case of need. Since most of these airports are located at some distance from the large centres, it is thought to use the important rivers flowing in the cities for the landing of the seaplanes: the Thames firsts. Similarly, rules are under consideration to facilitate ditching in English, French, Belgian and Dutch ports.

To highlight how much importance is given in England to the development of civil aviation, nothing better than to report the ideas that General Sykes, head of the Department, never misses the opportunity to proclaim:

«The conditions of the moment oblige the biggest economies; but an economy blind to the needs and importance of progress is not a true economy. A wise granting of financial encouragement in favour of collective services is a profitable use: this applies to the air transport industry; without the aid it would die and we would have to witness the disintegration of all the admirable personnel of scholars and builders formed during the war and the loss of what, at the potential state, is to military aviation what the merchant navy is to the fleet. Nothing has ever been done with the policy of "I cannot" ("non posso" in Italian) and it would be a serious harm for us to wait for a profit from the experience of other countries, which more than ours have rush and initiative. We have means to do; but what we need is the trust of all". Words that can square perfectly for us, too.

France, which arrived after England in the organization of a civil aviation, has all the air of soon reaching it, if not even to go beyond it, given the impetus that the State and private individuals pose to consider it as a problem of vital national importance. The system of large-scale subsidies in various forms into which the French State has courageously put itself, while in England there are still doubts and resistance in this regard, will soon bear fruit. Meanwhile, several companies, subsidized by the Government, are already in operation. I call four air transport companies between Paris and London (in addition to the English one mentioned) of which two do a daily service and the others on request, and we mention the Paris-Brussels, which has a postal surtax of 0.75 lira for $20 \mathrm{gr}$.

The entire Paris-Bordeaux route is now fully efficient, and this last city will soon be connected to the section BayonneBilbao, that a French company is handling in agreement with the Spanish Government. For several months we had a threeweek service from Toulouse to Tangier and Rabat, recently extended to Casablanca: a route of $1600 \mathrm{~km}$., with a postal surtax of $1.25 \mathrm{fr} / 20 \mathrm{gr}$. In the crossing of Spain, it makes a local mail service as well. Other operative lines are the Paris-Lille, Paris-Verdun, Bordeaux-Toulouse, etc.

A great air communications project is currently underway between Paris and Central and Southern Europe: the first section, Paris-Strasbourg-Prague, has already been inaugurated and the Prague-Warsaw trunks are being studied, and from Strasbourg to Vienna, Budapest, Belgrade, Bucharest and Constantinople. For this service, the Czecho-Slovak Government offered the Franco-Romanian Company a subsidy of 3.200.000 fr. and the Polish Government an indemnity of FR 3000 for each flight between Prague and Warsaw.

Recent news also let us know that France intends to give a strong boost to large-volume airships: 7 large hangars are being set up, and of these at least four on the Mediterranean area and, precisely, in Marseille, Toulon, Tunis and Bizerte. Can Italy be disinterested in such a fact?

In Belgium, a company has activated the Brussels-London service and in the Belgian Congo the «King Albert airline» has been established between Kinshasa and Stanley-Ville (1800 km. along the Congo River). There are four seaplanes for the transport of passengers, mail and goods; the entire journey takes 3 days instead of the 17 required by a river steamer.

In Netherland, the Royal Company of Transport is a postal service and is also linked with foreign companies. The city of Amsterdam has assumed the importance of an air communications hub: lines to London, Paris, Berlin and the Baltic, Swedish and Norwegian centres radiate or will radiate from it.

The Dutch are also preparing to set up airlines in the East Indies.

In Germany, initiatives have found serious obstacle in the clauses of the Peace Treaty and, moreover, it is not easy to get news on the going initiatives. However, it is certainly not risky to say that the German nation is preparing for intense air activity, in connection with the companies of Northern Europe. The route can be specified by two lines: Copenhagen-Hamburg-Bremen-Amsterdam and Berlin-Warnemünde-Malmo-Copenhagen.

It is also noteworthy the service performed by means of airships by D. E. L. A. G., with the cooperation of the 
Hamburg-American Line on the Berlin-Munich-Friedrichshafen line $(600 \mathrm{~km}$. in seven hours and at the price of 400 marks per person or with a postal surtax of $10 \mathrm{pf}$. per letter up to 20 gr.). The D. E. L. A. G., already before the war, had transported with airships over 40,000 passengers without the slightest accident and, therefore, gave the maximum entrust. But currently, the service is suspended for the application of the Peace Treaty. It also seems to be studying a line Berlin-Paris-New York, to be used for part of Hamburg-American Line with large-volume airships.

Even in Norway experiments were conducted during the summer months. An excellent service took place between Christianiaand Kristiansand and another coastal service from Stavanger to Bergen.

In the United States of America, in addition to the New York-Washington and the St Louis-Twin Cities lines and other minor ones, there is the great New York-S. Francisco line, which crosses the entire American continent, from the shores of the Atlantic to the shores of the Pacific. In October 1920 alone, $270,000 \mathrm{~km}$ were covered in total on this line. It is necessary to warn that they are only postal lines.

Another statistic then tells us that in the twelve months from July 1918 to July 1919, that is, before the introduction of the last advances in technology, in 1287 trips, with an average length of $200 \mathrm{~km}$., there were no more than 89 forced landings, (i.e. just over 6\%) of which 36 for engine failure and 53 for bad weather. It is, therefore, to be assumed that once the last failures will be almost totally eliminated with a good weather forecasting service and radiotelegraphic communication, it will remain only the first and, using multiengine devices, with an insignificant percentage.

To now review what is done in Italy there is to feel at the same time proud and discouraged.

Proud for the proofs of genius and courage that are given every day by those who look with faith at the future of civil aviation.

Discouraged both for the abandonment with which these few are left by the central government authorities, and for the distrust of which the great majority surrounds them. Germs are there and are alive and vital; but they are left to die.

In the field of science there is a State Body, the Aeronautical Experimental Institute, capable of carrying out fruitful work in collecting and ordering the fruits of the various national and international activities, both in guiding and coordinating the efforts that on all sides tend to the progress of technology and in studying and performing experiments. There are university activities, such as the Aeronautics Laboratory at the R. Politecnico in Turin, which spread the high scientific and technical culture among the Engineers. There is also a body that brings together the various individual energies, the Italian Association of Aerotechnics that, by placing them in contact with each other, increases and facilitates their activity. Finally, there are some journals ${ }^{3}$ really valuable for technical value, which does healthy work of vulgarization of aeronautical disciplines.

As for the constructions, of the numerous industrial houses ${ }^{4}$ that during the war turned their activity to them, those that today do something can be counted on the fingers of one hand. Spirit of initiative, value of technicians, skills of workers, efficiency of plants are not missing. But the market is closed: no one asks why no one believes they can fight the distrust of most and the apathy of the Government. And a lot could be done: the proof are recent types of civil aircraft, including the seaplanes M. 19 and S. 19, the large hydroaeroplane P.B. R, the land airplane A. 300 C., the small tourist aircraft with engines of 30 and 40 horses, etc.

No less bitter considerations we have been induced with regard to the activities of exercise. Suffice it to say that currently everything is suspended, everything is prohibited by the central authority, because there is no regulation governing the matter. Life is interrupted: the law will come to regulate it when it is extinguished. Abroad, as we shall see, this is certainly not the case.

And healthy initiatives would not be lacking: about ten companies are regularly set up for airline companies, and some of them in cooperative form. But only two, the National Air Propaganda (the P. A. N. of Rome) and the Società Anonima per Imprese Aeree Milano (S. A. I. A, M.) started a real activity, albeit limited to the sports field.

The first, however, despite having carried out a considerable tourist activity and transported many passengers on trips from Rome to Naples, is currently in crisis.

The second, on the contrary, has passed the critical period of the beginning and is heading towards success, without any help whatsoever from the State. In fact, owner of strong capital and directed by men of experience and action, it manages two splendid fields (Ancore and Erba-Incino): the two first civil airports in Italy; and has to its credit, in the five months from June to October 1920, a total of over $100,000 \mathrm{~km}$ of flight and 2408 passengers transported without the slightest accident. Noticeable are some flights such as Milan-Rome, Milan-Venice-Bologna-Milan, Milan-Venice-Trieste-Fiume, Milan-Geneva, etc. In addition to some aviatory days in the two airports, there were very successful days in Taliedo, Stresa, Lodi, which attracted tens of thousands of people to the fields and helped to spread the confidence and passion of flying in the public.

\footnotetext{
${ }^{3}$ Editor's note: The journal L'Aeronautica, when this report was compiled, had not yet ceased to exist. Founded in February 1918 with the name of L'Aeronauta, it changed it in 1920 to that of L'Aeronautica. It ceased in April 1921.

Editor's note: about 60 accounting both aircraft and engines manufacturers.
} 
The S. A. I. A.M. company has used land-based aircraft so far, belonging mostly to the production of war, and Macchi seaplanes of the commercial type; it waits for civilian aircraft to be built in Italy.

It is to be regretted that such a lively activity could only manifest itself sporadically, without assuming any regular service. What is the cause if not the lack of any encouragement, the lack of organized routes and all those services that make actual air navigation possible? Who is to blame, if not the State, which only can provide for these needs and does not provide for them? Can we hope that the admirable deeds of our beautiful aerial machines will finally win so many obstacles?

And in the field of the lighter than air, we remember the tourist services carried out with airships, with the same airships that had dropped bombs on the enemy. The M. 1 alone made over 1800 passengers enjoy the joys of the flight, carrying 564 of them in the only month of June 1919, over 30 per ascension, and, in a test, sailing with 54 men on board. If you add the activity of the M. 14, of the F. 6, of P. V. 1, etc. not less than 3000 shall be the number of passengers carried by airships; and without the slightest incident.

It is almost useless to recall the last airship launched by the plant Costruzioni Aeronautiche: the "Roma" airship of type T. 34. After the test with an uninterrupted flight of $1200 \mathrm{~km}$. (Rome-Palermo and back), almost everything on the sea, it was requested for purchase by the United States of America. And it is not the only affirmation abroad: England, France, the United States, Argentina, and Spain have purchased airships and Italian observer balloons; in the Races of Antwerp and in the Gordon Bennet held lately in America very distinguished our spherical led by our pilots; the other nations envy us our constructions of the lightest: the A.P. observatory balloon has now surpassed the previous similar German and French types.

Erasing with the present a glorious past, letting so much energy die of a slow death, is a real crime.

\subsection{What Italy must Do}

The first thing is to pay more attention to studies and to the progress of technology.

Now the progress of aeronautical science does not need much help: it needs not find continuous hindrances. Italy does not lack men capable of contributing effectively to the intense work that is carried out all over the world for the formation of such a science: even in this field the spirit of initiative and the genius of the people are not lacking.

But two things are lacking in Italy: the coordination of forces and the necessary freedom of action. Let scientists be taught a way to study, technicians should be taught a way to build and experiment, and progress will accelerate its pace in Italy too.
But a doubt arises: can the economic conditions of our country allow such a luxury? Should we not be glad to ask charity abroad for the discoveries that come to light every day? There is not much need to be done: little should be done, but it should be done well. A false economy is one that, for momentary petty savings, risks the loss of a precious asset. And truly precious is the heritage constituted by the experience, by the particular attitude of technicians and workers, by the particular equipment of plants.

If needed, let the quantity be reduced for the sake of quality; but do not destroy everything. We will regret it bitterly the day that, forced by necessity, we had to reach the other nations, which will have left us far behind by who knows how far.

Do not, therefore, deny the State the very little time necessary to keep studies and technology alive!; do not neglect the teaching of the new aeronautical disciplines, so that it extends the set of their experts; do call on all the vital energies of the country to contribute to the solution of the most important problems.

All this can be done with much, much less than the 130 million francs that France has allocated to the Civil Aeronautics. Our nation, less than others favoured by nature, is used to achieving great goals with scarce means: this can also be done for aeronautics. Just want it!

A second providence to be exercised by the State could be a support towards the initiatives and the air transport enterprises and, also, towards the national aeronautical industry, shaken by a deep crisis. ${ }^{5}$

It has been seen in the previous pages that there is no lack of people who would like "to do"; but they can't. Using a technical term, we would say that Aeronautics is in a deadlock: it needs an impulse to get it out. It can only be the State. This is the case with the old commonplace: let the government does what private initiative cannot do.

Let us not talk, for example, about services provided by the State, if you do not want to increase the number of disastrous tests that state industries have given and will continue to give.

A state-owned aeronautical enterprise would produce two damages: first, after a period of stunted life and burdensome for the Treasury, the bankruptcy; second, the satisfaction from foreign countries, which would not find such a frightening competitor in State. The State must not become the manager, but only large and generous supporters of air companies.

Although, perhaps, another means could solve the problem of overcoming that deadlock without even needing

\footnotetext{
5 Editor's note: On the topic of aid to industry, which has barely been touched on in the present report, see the agenda of 3 February 1922, in the appendix to this volume.
} 
government help: the initiative of a powerful financial group, able to withstand the first inevitable liabilities of start-up and connected, on the one hand, with the cooperative groups of technicians and pilots and, on the other one, with sports associations.

Let us look at what Germany is doing: despite the very serious obstacles raised by the Peace Treaty, it is preparing for the future by directing the activities of those same large companies that in the past ensured its power at sea to conquer the sky. And the day is perhaps not far off when we will see an impressive air fleet connecting Germany with the whole world, establishing very rapid communications, opening new outlets for its industrial activity.

Italy must beat the same path. A very noble purpose must spur it on, that is the increasingly intimate connection to the Mother Land of the Italian centres scattered throughout the world, especially in America. These sons of Italy, who, also with their own individual fortune cooperate to the good of the homeland, with such a contribution of works cooperate, would greet with joy the direct communications through the ways of heaven. It would be difficult to find more intimately united the reasons for feeling with those of the national interest.

Let us, therefore, repeat that the future of air transport is in world communications across continents and oceans. Modest initiatives will not be enough for this: we need forward-looking activities, backed up by large amounts of capital, linked to similar companies in other nations.

Will our shipowners direct their energies in this field? For the good of Italy, we hope so.

But major initiatives must be preceded by assiduous preparation. It needs that Technology needs to take the fruits of its progress. It needs those services, even initially limited, must provide an opportunity to gain experience for the future.

Therefore, even the most modest initiatives are of great importance: they contain the future in the germ. We must not hinder them but help them where they do not necessarily support themselves.

In the first place, the State will have to lend the help of its technical bodies, and, where necessary, to yield the work of its best specialists. Second, it will have to ensure the organization of all air navigation services. Third, it will have to cooperate, with appropriate large subsidies, for the good fortune of companies. Fourth, it will have to arouse the confidence of the public with a means which may at first seem more like a stumbling block than an aid, but which, if kept within the appropriate limits, will certainly produce beneficial effects, namely with the control of the constructions and the examination of the suitability of the pilots. These are very delicate functions but which, wisely carried out and while not in any way exonerating the manufacturers and conductors of aircraft from their responsibilities, give the State the opportunity to exercise a high vigilance, and to offer an indispensable guarantee.

A final provision of the State is the organization of ground services. As with seaports and major roads, the State must provide for airports and air routes. These installations are part of that civil activity, preparatory to the eventualities of a war. How could airplanes and airships immediately start an effective offensive or protective service, without airfields, hangars, repair and refuelling posts? None of this can be improvised. In short, maybe that cooperative bodies will be set up to provide such services on the ground; and then the State will take care only of installations of military importance. But, for now, it will have to do everything or nothing will be done.

Another service of primary importance is the areological one for information and weather forecasting. It informs on the weather conditions that an aircraft will encounter during the journey; it indicates the route to be followed, the altitude to be chosen, the precautions to be taken; it greatly elevates the regularity of each air transport company. This service is a state task, even more so since it is not just for aeronautics, but for marine navigation, agriculture, etc. It has the same importance of signals for the railway: it indicates the state of the atmospheric region to be crossed. How many times would a simple phone call have avoided big troubles!

And here it is already stated the importance of the media for communication of news: communication to the airfields, to the departing aircraft, to the aircraft in flight. An organic radiotelegraphic service is thus required, which will directly connect the airports to each other and to the areological bodies and connect the aircraft to the ground. Those who have ventured into the sky in the darkness of the night or in the darkness of the fog, know what it means receiving news, encouragement or the precise indications of the route. In fact, this is what we come to: the radiogoniometry has solved the problem.

\subsection{Conclusion}

Is there a need to draw it?

Who will have the dominion of heaven, will be the master of the world. Without proper aeronautics, a Nation cannot be great.

Nation, it has been said: in fact, a government cannot maintain a powerful weapon of the sky. Great development can have aeronautics only where it finds food, that is in the civil commercial field.

Many do not believe it. Everyone will be forced to believe it. And in a very short time: foreign nations will force. 
It is a commonplace: the geographical position of Italy imposes strong destinies on it. You have to decide either among the strong destiny or be a slave of abroad.
Publisher's Note Springer Nature remains neutral with regard to jurisdictional claims in published maps and institutional affiliations. 